\begin{tabular}{c|cc|}
\hline $\begin{array}{c}\text { ADVANCE RESEARCH JOURNAL OF SOCIAL SCIENCE } \\
\text { Resticle }\end{array}$ & $\begin{array}{c}\text { Volume 6 | Issue 2 | December, 2015 | 165-172 } \\
\text { e ISSN-2231-6418 }\end{array}$ \\
\hline DOI: 10.15740/HAS/ARJSS/6.2/165-172 & Visit us : www.researchjournal.co.in
\end{tabular}

\title{
Impact of perceived loneliness on emotional intelligence among rural and urban adolescents
}

\author{
Parul Joshi* and Tejpreet Kaur Kang
}

Department of Human Development, Punjab Agricultural University, LUDHIANA (PUNJAB) INDIA

\begin{tabular}{lrl}
\multicolumn{2}{l}{ ARTICLE INFO : } \\
$\begin{array}{lrl}\text { Received } & : & 26.06 .2015 \\
\text { Revised } & : & 20.10 .2015 \\
\text { Accepted } & : & 01.11 .2015\end{array}$
\end{tabular}

KEY WORDS :

Loneliness, Emotional intelligence, Adolescents

\section{HOW TO CITE THIS ARTICLE :}

Joshi, Parul and Kang, Tejpreet Kaur (2015). Impact of perceived loneliness on emotional intelligence among rural and urban adolescents. Adv. Res. J. Soc. Sci., $6(2): 165-172$.

*Author for correspondence

\begin{abstract}
In the present investigation an attempt has been made to study the impact of perceived loneliness on emotional intelligence among rural and urban adolescents. The study was conducted on 200 adolescents (100 boys and 100 girls) in the age range of 15-18 years residing in the rural and urban areas of Ludhiana. Perceived Loneliness Scale developed by Jha was used to assess the incidence and extent of loneliness present in adolescents. The scale consisted of 36 items covering various factors relating to parental behaviour, peer relations, human need for intimacy, people's perception, evaluation of social relations, insufficient social reinforcement, physical surroundings, preference of a particular sibling, neglecting, isolating and criticizing nature of parents. Emotional Intelligence Scale by Hyde et al. (2002) was used to assess the emotional intelligence (EQ) of the adolescents. The scale had 34 statements under 10 dimensions of emotional intelligence i.e. self-awareness, empathy, self motivation, emotional stability, managing relations, integrity, self development, value orientation, commitment and altruistic behaviour. Data were analyzed using Karl Pearson's co-efficient correlation and Linear Regression. Results revealed that there is non-significant correlation between dimensions of emotional intelligence and loneliness among rural males and urban adolescents and significant correlation between dimensions of emotional intelligence and loneliness among rural females. Linear regression revealed that the feeling of loneliness was negatively significantly affecting the aspects of emotional intelligence among rural and urban adolescents.
\end{abstract}

